\section{A self-determination theory approach to technology-enhanced out-of-class language learning intention: A case of Japanese EFL learners}

\author{
Fathali, Somayeh $\bowtie$ \\ Tohoku University, Japan (somayeh.fathali.p7@dc.tohoku.ac.jp) \\ Okada, Takeshi \\ Tohoku University, Japan (takeshi.okada.a8@tohoku.ac.jp)
}

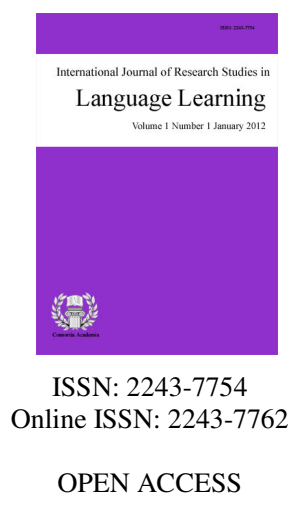

Accepted: 6 September 2016

Received: 14 August $2016 \quad$ Revised: 21 August 2016

Available Online: 12 September $2016 \quad$ DOI: 10.5861/ijrs1l.2016.1607

\title{
Abstract
}

The purpose of this study was to investigate Japanese EFL learners' intention to continue technology-enhanced out-of-class language learning (OCLL). Concerning the strong mutual relationship between the learners' motivation and their intention for learning, this study drawing on self-determination theory (SDT), proposed and tested a model of the relationship between the motivation determinants and the learners' intention toward technology-enhanced OCLL. The research was conducted in an EFL Japanese context of 164 undergraduate students participating in general English classes equipped with technology both inside and outside of the classroom. The findings of the structural equation model indicated the positive effect of motivation determinants (competence, autonomy, and relatedness) on the learners' intention to continue OCLL, among which perceived competence was the most significant predictor. Additionally, the model examined how the motivation determinants could explain the learners' actual achievements. The results provided evidence that perceived relatedness could not influence the learners' OCLL achievements. The findings and implications are discussed.

Keywords: blended learning environments; out-of-class language learning; self-determination theory; web-based e-portfolio; continuance intention 


\section{A self-determination theory approach to technology-enhanced out-of-class language learning intention: A case of Japanese EFL learners}

\section{Introduction}

The rapidly growing interest in technology-based learning contexts among EFL teachers and learners has resulted in the combination of traditional classrooms with the vast use of computerized teaching and learning methods known as blended learning environments. As noted by Neumeier (2005), blended learning environments are normally composed of two modes of delivery: face-to-face (F2F) and computer assisted learning (CAL). However, the crucial point is that normally these two modes are combined and studied inside the classroom and literature lacks enough research and investigation in the technology-enhanced out-of-class language learning (OCLL) environments (Benson, 2001; Benson, 2011; Richards, 2015), especially in EFL contexts where learners have very little or no exposure to English beyond the classroom. Therefore, this study aims to provide insights into the EFL learners' intention to continue technology-enhanced OCLL-using a web-based e-portfolio system-through self-determination theory perspective (SDT, Deci \& Ryan, 1985).

\section{Literature review}

\subsection{Out-of-class language learning (OCLL)}

According to Richards (2015), "there are two important dimensions to successful second language learning: what goes on inside the classroom and what goes on outside of the classroom" (p.1). Findings from previous studies provide evidence that out-of-class study has a significant role in language learning process and it can enhance learners' educational output in multiple ways (Fathali \& Okada, 2016; Chang, 2007; Lai \& Gu, 2011; Yoon, 2012).

Benson (2001) defines OCLL as the autonomous learning achievements accomplished at any time and in any place regardless of the conventional classroom borders. He refers to three types of OCLL: self-instruction learning (learners deliberately plan to learn a language), naturalistic learning (learners learn a language while they are engaged in an activity without specific focus on learning), or self-directed naturalistic learning (learners intentionally engage in activities to learn a language through that engagement). In this view Benson puts emphasis on the learners' role and willingness to invest time and effort into independent learning beyond the class. In addition, Reinders (2014) argues that learners' success in independent language learning using the available technology largely depends on their behavioral intention to carry out self-study. However, despite the significance of the learners' intention for independent learning (Mobarhan, Majidi, \& Abdul Rahman, 2014; Reinders, 2014; Richards, 2015), this issue has not received enough empirical scrutiny in OCLL environments.

\subsection{Motivation and OCLL intention}

Based on the cognitive theories of motivation and action being motivated to act is equal to having an intention to engage in an action (Deci, 1975). Ellis (1994) suggests that motivation is "the effort which learners put into learning an L2 as a result of their need or desire to learn" (p. 175). Consequently, regarding the strong mutual relationship between motivation and learners' intention for an action, investigating proper ways to facilitate motivation can contribute to our understanding of the means to promote intention.

Literature shows that there are different theories of motivation which share overlapping concepts and characteristics, and have roots in the learners' cognitive beliefs and expectations (Murphy \& Alexander, 2000; Pintrich \& Schunk, 2002; Schunk \& Zimmerman, 2006). However, concerning the shared concepts among these 
A self-determination theory approach to technology-enhanced out-of-class language learning intention

theories, Schunk and Zimmerman (2006) believe that they can be categorized into five well-developed theories, including achievement theory, attribution theory, social-cognitive theory, goal-orientation theory, and self-determination theory. Although these theories share parallel ides about motivation, they explain it from different perspectives. Among the above mentioned theories, self-determination theory (SDT, Deci \& Ryan, 1985) refers to the individual's ability to choose how to satisfy their needs and perform actions that need some degree of self-regulation. Therefore, since out-of-class learning is mainly influenced by self-determined behaviors and self-regulated actions (Mobarhan et al., 2014; Reinders, 2014), this study tries to investigate how well this theory, i.e. SDT, applies to and explains Japanese EFL learners' intention to continue technology-enhanced OCLL.

SDT being applied in numerous educational (Chen \& Jang, 2010; Lai, Wang, \& Lei, 2012; Zhou, 2016) and non-educational settings (Lee, Lee, \& Hwang, 2015; Roca \& Gagne, 2008; Yoon \& Rolland, 2012), through the sub-theory of cognitive evaluation, argues the significance of contextual support and satisfaction of the essential needs to maximize intrinsic motivation. This theory focuses on competence, autonomy, and relatedness as the three basic psychological human needs that can facilitate intrinsic motivation. The need for competence is the individual's need to feel capable of effective performance, and achieving one's goals. The need for autonomy implies the intention to feel free to choose and control one's own actions. Finally, the need for relatedness is to feel connected to others through proper interaction and cooperation (Deci \& Ryan, 1985; Vallerand, 1997). Hence, in line with SDT, the present research tries to investigate the effect of the three motivation determinants on the learners' intention to continue language learning beyond the classroom, as well as the learners' actual performance in a technology-supported context which in this case is a web-based e-portfolio system.

\subsection{Research model}

Based on SDT, previous studies have presented several models indicating relationships between individuals' achievements and satisfaction of their basic needs in different contexts. For instance, Chen and Jang (2010) tested a model of self-determination theory in two online teaching certificate programs to examine online learners' motivation. Yoon and Rolland (2012), drawing on SDT, investigated a model of the effect of needs satisfaction on knowledge-sharing behaviors in virtual communities, and Zhou (2016) examined a model of SDT integrated with theory of planned behavior for the learners' intention to use massive open online courses (MOOCs) for learning. However, there is no research on the relation between the satisfaction of the basic physiological needs and language learners' intention toward autonomous technology-enhanced out-of-class study. Accordingly, drawing on SDT, the proposed research model in this study tests how the satisfaction of these needs can predict the learners' intention to further OCLL using technology, and their actual out-of-class performance, respectively (Figure 1).

Researchers argue that learners' engagement in doing activities is highly affected by self-determination and satisfaction of their innate needs for competence, autonomy, and relatedness (Grolnick, Ryan, \& Deci, 1991; Chen \& Jang, 2010; Roca \& Gagne, 2008; Urdan \& Turner, 2005). Vallerand and Bissonnette (1992) argue the positive effect of self-determination on the student's continuance intention to achieve their academic goals. When learners have a sense of competence in performing an activity on their own; feel they are the origin of their own decisions; and feel connected to other group members, their intention to continue would be enhanced (Deci \& Ryan, 1985; Roca \& Gagne, 2008). Hence, based on the abovementioned concepts, hypotheses 1, 2 and 3 of the research address the intention of the learners to continue OCLL as the product of self-determination indicators.

H1. Learners' perceived competence can positively predict their intention for technology-enhanced OCLL.

H2. Learners' perceived autonomy can positively predict their intention for technology-enhanced OCLL.

H3. Learners' perceived relatedness can positively predict their intention for technology-enhanced OCLL.

Previous studies reveal that satisfaction of the psychological needs could be positively related to the 
Fathali, S., \& Okada, T.

individuals' outcomes (Jeno \& Diseth, 2014; Chen \& Jang, 2010). As a result, hypotheses 4, 5 and 6 of the study propose that perceived competence, autonomy, and relatedness can positively predict the learners' actual achievements in the technology-enhanced OCLL.

H4. Learners' perceived competence can positively predict their OCLL achievements.

H5. Learners' perceived autonomy can positively predict their OCLL achievements.

H6. Learners' perceived relatedness can positively predict their OCLL achievements.

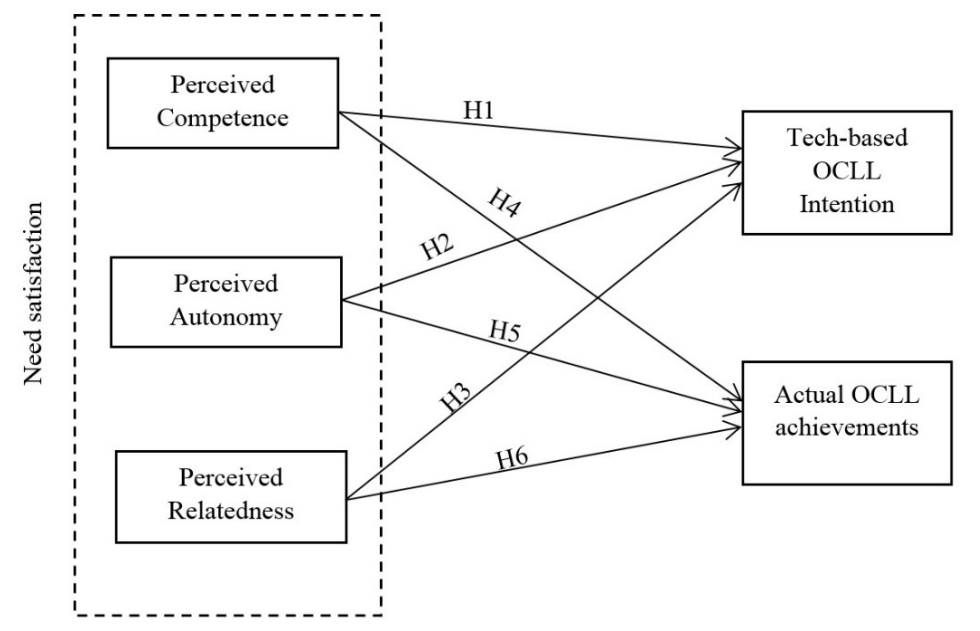

Figure 1. Hypothesized model of the research

\section{Method}

\subsection{Participants}

The study was conducted in one of the Japanese national universities, and the participants were EFL undergraduate students attending general English courses. Three general English classes were randomly chosen with a total of 164 students majoring in engineering $(\mathrm{N}=32)$, law $(\mathrm{N}=56)$ and science $(\mathrm{N}=78)$. Students' age ranged from 18 to $21(\mathrm{M}=18.90, \mathrm{SD}=.87)$, of whom $135(82.31 \%)$ were male. The majority of the students were freshmen $(81.7 \%)$ and the rest were sophomores. Considering the number of the variables in the survey questionnaire, this number of participants could fit the rule of thumb for performing a structural equation model (Hair, Black, Babin, \& Anderson, 2010).

\subsection{Research context}

In the context of the present study, general English classes were held twice a week, each session 90 minutes and each semester lasted for almost 4 months. The participants practiced reading skill of TOEFL ITP ${ }^{\circledR}$ test in an e-learning environment inside the classroom using an interactive blended English language enhancement system (iBELLEs, Okada \& Sakamoto, 2015). The participants also continued reading practice outside the class through a web-based e-portfolio system (Fathali \& Okada, 2016). The learners could access both systems on the university's learning management system called WebOCMnext. Since OCLL is the main concern of this paper, here is a brief explanation of the web-based e-portfolio system.

The system was designed with the integration of Google Sites as the collaborative space and Google Drives as the learners' personal learning environments. The system's main website (Google Sites) consisted of different webpages that supported learners' autonomous learning such as:
A page
including a
link to the Cambridge
English language
assessment website 
A self-determination theory approach to technology-enhanced out-of-class language learning intention

(http://www.cambridgeenglish.org/test-your-english/adult-learners/) that directed each learner to an online test, of which the final score was interpreted according to the Common European Framework of Reference for Languages (CEFR). Hence, it could help the learners find their level of English language proficiency and following that the reading materials appropriate to their levels independently.

$>$ A page including a list of pedagogically and academically approved EFL learning websites.

$>\quad$ A page for the instructors' weekly feedbacks on the learners' assignment submissions, in addition to the crucial points figured out through weekly monitoring of the e-portfolios. The instructors tried to investigate common learning obstacles and eliminate them by referring the learners to different online training materials.

$>\quad$ A page guiding the learners through self-assessment and setting future learning goals.

$>\quad$ A page in which all the learners' individual pages were brought together and categorized randomly into groups for the easier access. Each learner had an individual webpage linked to his/her personal e-portfolio created in Google Drives. The individual pages enabled receiving instructors and peer feedback on the weekly assignments.

Each learner uploaded a weekly file of their reading practice, including the links to the passages they read and their preferred post-reading activities performed after reading. The post-reading activities such as writing summaries, listing newly learned words, making questions, describing information, etc. could help the learners actively interact with the texts and boost their learning outcomes (Rivas, 1999). Though the learners had access to all the members' e-portfolios and could provide comments, they were also randomly assigned into pairs to ensure everyone would at least receive weekly comments once.

\subsection{Measures}

The data was collected using an online questionnaire adapted from relevant measures used in previous studies. All the items were measured on a 7-point Likert scale ranging from 1 (strongly disagree) to 7 (strongly agree), and they were slightly modified to fit the context of this study.

Learners' perceived competence was measured using 6 items adapted from intrinsic motivation inventory (IMI, McAuley, Duncan, \& Tammen, 1989), of which a sample item was "I think I was pretty good at learning English beyond the class using technology". Learners' perceived autonomy was assessed through 4 items selected from Standage, Duda, and Ntoumanis (2005), with a sample item of "I feel a certain freedom of action in learning English beyond the class using technology". To measure learners' sense of relatedness 5 items from South's (2006) sense of community instrument were used with a sample item of "I felt that other classmates had similar goals to mine in learning English beyond the class using technology". Learners' intention to continue technology-enhanced OCLL was measured using 3 items adapted from Venkatesh, Morris, Davis, and Davis (2003), of which a sample item was "I intend to continue learning English independently beyond the class using technological devices". Finally, learners' actual achievements in OCLL process was figured out by the total number of the eligible e-portfolio files in each learner's personal Google Drive, in addition to the number of his/her interactions in the class website.

\subsection{Data analysis}

The preliminary screening of the data for unengaged responses and outliers did not detect any missing data. Exploratory factor analysis (EFA) with maximum likelihood extraction technique was conducted to test the appropriateness of the items of each subscale of the research questionnaire. Cronbach's alpha reliability analysis was then calculated to examine the internal consistency of the subscales of the questionnaire based on the data of this study. Reliability and validity of the constructs in the measurement model were examined through 
Fathali, S., \& Okada, T.

confirmatory factor analysis (CFA). Composite reliability (CR) was computed to examine the reliability of the constructs in the measurement model which, according to Bagozzi and Yi (1988), should exceed 0.6 to represent an acceptable level of reliability. Convergent and discriminant validity were applied and tested according to Fornell and Larcker (1981). They believe that the convergent validity of the constructs is confirmed when all the items have factor loadings higher than 0.6 (Hulland, 1999), and in order to verify the discriminant validity, the square root of the extracted average variance (AVE) should greatly exceed the correlation between each construct with the other constructs.

After the analysis of the measurement model, path analysis was conducted to investigate the multivariate relation between the constructs in the hypothesized model using SPSS ${ }^{\circledR}$ AMOS 23, a software package for conducting a structural equation model approach to path analysis. To estimate how well the initial model fitted the data, according to Hair et al. (2010), five goodness of fit indices were evaluated, including chi-square coefficient $\left(\chi^{2}\right)$, comparative fit index (CFI), Tucker-Lewis Index (TLI), standardized root mean square residual (SRMR), and root mean square error of approximation (RMSEA). A good fit would be achieved by insignificant chi-square test results, a CFI and a TLI value greater than .95, an SRMR and an RMSEA value less than .08 (Hair et al., 2010).

\section{Results}

The descriptive data of the questionnaire items including mean, standard deviation, factor loading, composite reliability, and Cronbach's alpha coefficient are presented in table 1. Since the low factor loading of item 6 in the perceived competence scale caused some cross loadings in the EFA, this item was removed from the measurement scale and the rest of the analysis. As represented in table 1, the results of the Cronbach's alpha reliability analysis indicated high internal consistency among the items of each subscale $(\alpha>0.8)$. Composite reliability of each construct resulted in a good level of reliability for each construct (CR $>.75)$. The satisfactory factor loadings (higher than 0.6) of all the items of the questionnaire confirmed the convergent validity of the constructs (Hulland, 1999). Correlations represented in table 2 showed an adequate difference between the square root of the variance (AVE) and all other correlations for each construct, thus, the discriminant validity of the constructs was verified.

Figure 2 presents the results of the structural model with the standardized path coefficients. The fit indices suggested that the research model had an acceptable fit to the data, $\chi^{2}(125)=165.843$, ns, CFI $=.973$, TLI $=.967$, SRMR $=.04$ and RMSEA $=.04$. The paths in figure 2 indicate that intrinsic motivation determinants of SDT, perceived competence $(\beta=.70, \mathrm{p}<0.01)$, perceived autonomy $(\beta=.37, \mathrm{p}<0.01)$, and perceived relatedness $(\beta=.16, p<0.01)$ could positively influence the learners' intention toward technology-enhanced OCLL, therefore, hypothesis 1-3 was supported by the research model. These determinants explained $43 \%$ of the variance in technology-enhanced OCLL and 27\% of the variance in the learners' actual OCLL performance. Learners' actual performance could be predicted by their perceived competence $(\beta=.25, \mathrm{p}<0.01)$ and perceived autonomy $(\beta=.16, p<0.05)$, supporting hypothesis 4 and 5 . However, perceived relatedness could not significantly influence learners' actual performance $(\beta=.11, \mathrm{~ns})$, and hypothesis 6 was not supported by the model.

\section{Table 1}

The descriptive statistics of the measurement constructs

\begin{tabular}{lllllcc}
\hline Construct & Item & Mean & SD & Factor loading & Cronbach $\alpha$ & CR \\
\hline Perceived Competence & & & & & 0.89 & 0.89 \\
& PComp_1 & 4.87 & .880 & .951 & \\
& PComp_2 & 4.74 & .885 & .893 & \\
& PComp_3 & 5.09 & .882 & .721 & \\
& PComp_4 & 5.01 & .943 & .685 & \\
& PComp_5 & 5.02 & .953 & .612 & \\
& PComp_6 & 4.28 & .859 & .591 & & \\
\hline
\end{tabular}


Table 1 ... continued

\begin{tabular}{|c|c|c|c|c|c|c|}
\hline \multicolumn{5}{|l|}{ Perceived Autonomy } & 0.81 & 0.82 \\
\hline & PAut_1 & 4.68 & .978 & .774 & & \\
\hline & PAut_2 & 5.23 & .963 & .758 & & \\
\hline & PAut_3 & 4.53 & 1.024 & .744 & & \\
\hline & PAut_4 & 4.70 & 1.018 & .632 & & \\
\hline \multirow{6}{*}{ Perceived Relatedness } & & & & & 0.91 & 0.91 \\
\hline & PRel_1 & 4.35 & .898 & .901 & & \\
\hline & PRel_2 & 4.29 & .953 & .880 & & \\
\hline & PRel_3 & 4.12 & .782 & .823 & & \\
\hline & PRel_4 & 4.15 & .826 & .819 & & \\
\hline & PRel_5 & 4.21 & .827 & .691 & & \\
\hline \multirow[t]{4}{*}{ Intention } & & & & & 0.88 & 0.79 \\
\hline & Int_1 & 6.01 & .641 & .846 & & \\
\hline & Int_2 & 5.83 & .706 & .758 & & \\
\hline & Int_3 & 6.15 & .578 & .623 & & \\
\hline
\end{tabular}

Table 2

Correlation matrix and average variance extracted

\begin{tabular}{lllll}
\hline Construct & $\begin{array}{l}\text { Perceived } \\
\text { Competence }\end{array}$ & $\begin{array}{l}\text { Perceived } \\
\text { Autonomy }\end{array}$ & $\begin{array}{l}\text { Perceived } \\
\text { Relatedness }\end{array}$ & Intention \\
\hline Perceived Competence & $0.62^{\mathrm{a}}$ & & & \\
Perceived Autonomy & .405 & 0.53 & 0.68 & \\
Perceived Relatedness & .350 & .335 & .260 & 0.56 \\
Intention & .347 & .264 & .251 & .076 \\
Actual Performance & .359 & .285 & & \\
\hline Note. ${ }^{a}$ Square root of average variance extracted (AVE).
\end{tabular}

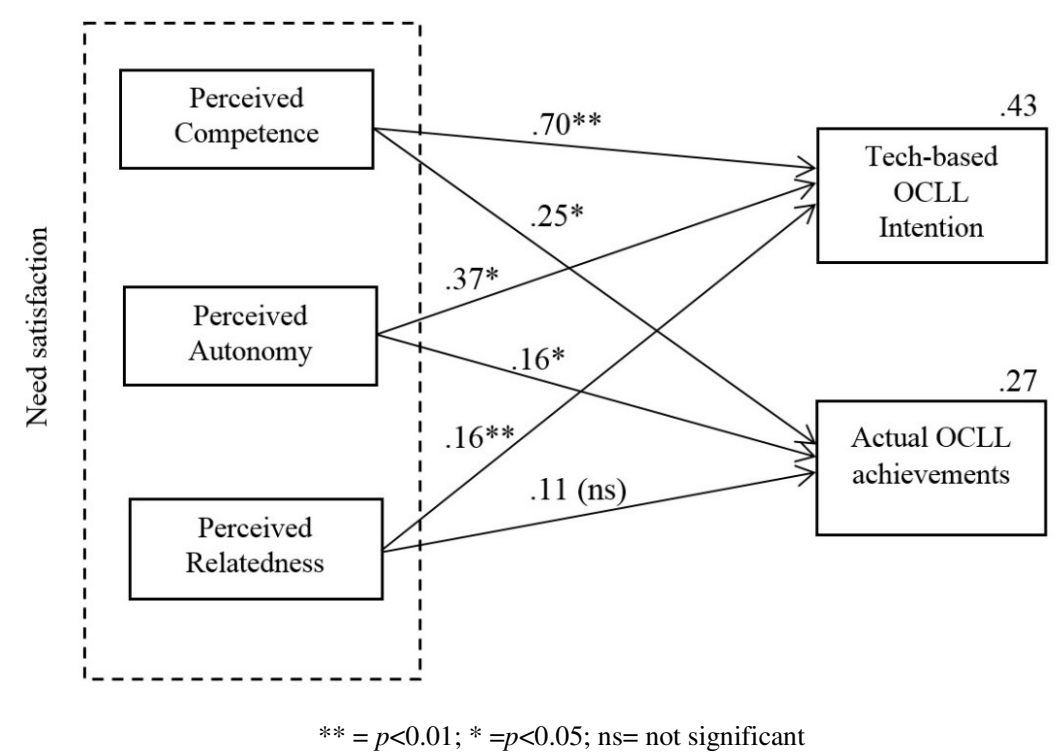

Figure 2. Final structural model (standardized path coefficients)

\section{Discussion}

The present study was conducted to provide an empirical testing of SDT in a technology-enhanced OCLL mode of a Japanese EFL blended learning environment equipped with a web-based e-portfolio system. In line with SDT, the final research model indicates that satisfaction of the learners' basic needs for competence, autonomy, and relatedness that facilitate intrinsic motivation (Deci \& Ryan, 1985) can positively influence the learners' intention to carry out technology-enhanced OCLL. Forty-three percent of the variance of the learners' 
intention for OCLL is explained by the determinants of SDT, which suggests that SDT can be an appropriate theoretical framework in the technology-enhanced OCLL contexts. This result is in line with previous studies which approved the supporting effect of basic needs satisfaction in SDT domains (Baard, Deci \& Ryan, 2004; Deci et al., 2001; Roca \& Gagne, 2008). Therefore, if instructors are interested in increasing learners' intention to carry out independent learning beyond the class, they can focus on creating OCLL environments which can help learners feel their three basic psychological needs are fulfilled. The values figured out in the research model also indicate the significance degree of these needs from the learners' perspectives.

The findings of the structural model show that perceived competence has the strongest effect on the learners' intention to continue technology-enhanced OCLL, as well as their actual achievements. Therefore, the most important issue is to invest time and effort in finding ways to help learners feel competent and capable of achieving their goals independently. Instructors need to choose or design technological devices in accordance with the learners' basic technological abilities and educational levels in order to keep them feel competent through the process. Although OCLL takes place beyond the classroom and in many cases beyond the teachers' responsibilities, learners need to receive teachers' support especially in the beginning stages of learning. Deci and Ryan (2010) argue that teachers' positive feedback as a verbal reward would also make the learners feel capable of accomplishing their objectives. Hence, we suggest that creating an interaction-supportive virtual environment in which not only instructors, but also learners would be trained and encouraged to provide positive feedback on the other community members' performance can maximize learning intention. Moreover, learners' responsibility for regular feedback on the other users' works can be another way to promote their confidence in their abilities and consequently facilitate their sense of competence.

The results also reflect the strong association between perceived autonomy and the learners' intention toward learning, in addition to their final achievements. In line with previous research, learners' sense of control over their own learning process can improve their willingness to continue independently (Deci \& Ryan, 1985; Vallerand, 1997). Even though learners require instructors' support in OCLL contexts, the results indicate that they also value their sense of autonomy as their second need to be fulfilled. Consequently, instructors need to find ways in which they can support learners and at the same time give them some degree of responsibility to control their own learning. We suggest that the sense of autonomy can be promoted in different ways, for instance, a) assisting learners to independently find their own proficiency level and following that offering them the chance of choosing among a wide range of learning materials and activities based on their own levels, $b$ ) guiding them through regular evaluation of their own achievements, c) supporting them through goal developments based on their self-evaluations. In this way learners would also be prepared to gradually transfer from the teacher-supported environment to continue their independent learning (Reinders, 2014).

Although the third motivation determinant-perceived relatedness-is not considered as a crucial predictor as perceived competence and perceived autonomy for the intrinsic motivation (Deci \& Ryan, 2010), the findings of this study reveal that it can positively and significantly influence the learners' intention for OCLL, though with less degree of importance. The significant path from perceived relatedness to learning intention suggests that feeling connected to instructors and other classmates even outside of the classroom can facilitate learners' intention to continue learning. Since this learning happens beyond the class, where learners may be in different places and at different times, belonging to a community of other members who also carry out the same leaning process and desire to achieve the same goals can maximize learning intention. Therefore, instructors can bring the learners together into a shared virtual space, so that not only they feel connected to other classmates but they can also observe others' accomplishments and at the same time being observed and valued by others.

Furthermore, the model indicates that the learners' actual OCLL achievements are explained by SDT in which $27 \%$ of the variance of their performance is defined by perceived competence and perceived autonomy. Sense of relatedness can positively predict the learners' intention for OCLL, but contrary to our expectations and previous studies (Jeno \& Diseth, 2014; Chen \& Jang, 2010), the learners' actual achievements are not influenced by their perceived relatedness. Since relatedness can positively influence their OCLL intention, it is expected 
A self-determination theory approach to technology-enhanced out-of-class language learning intention

that it can in turn result in a better outcome. In our opinion, there may be different reasons for this finding. The first can be related to the features associated with the implemented web-based e-portfolio system. The design of the system emphasizes the sense of connectedness in addition to the individuality of the learners by having an individual e-portfolio (Barrett, 2006, 2007; Lorenzo \& Ittelson, 2005). All the learners are connected to each other in the classroom website, follow an identical process of learning, interact regularly, and influence each other's performance. However, learners identify their own learning progress with their own distinct learning styles in the personal e-portfolios. Hence, the learners' performance is not significantly influenced by the other community members. The second can be related to the learners' language proficiency level. The initial language proficiency test indicated that $83 \%$ of the learners were at the same level of English language proficiency (B1-B2, according to CEFR). Therefore, it can be explained that due to the same level of proficiency, learners' relatedness cannot be an influential factor for their actual achievements. The third reason can be related to the Japanese students' cultural beliefs and educational system. Similar to many Asian learners, Japanese EFL learners are accustomed to the teacher-centered learning environments (Hirata, 2010). Therefore, peer-supported language learning is not highly valued by the learners. However, this issue is still under investigation and more scrutiny is being applied to clarify the findings.

\section{Conclusion and implications}

In summary, the current study could successfully confirm the relationship between self-determination theory indicators and the learners' intention toward technology-enhanced OCLL. It demonstrates the importance of focusing on the motivational aspects in order to increase learning intention in self-study contexts. Consequently, this study has implications for researchers interested in studies in technology-enhanced OCLL domains by guiding them to implement SDT as the theoretical framework of their research. The results also contribute to our understanding of Japanese EFL learners' perceptions about the prominence of their psychological needs for competence, autonomy and relatedness, among which competence is the first and autonomy is the second highly valued needs by the learners. The findings can also have implications for language teachers (instructors) by providing insights into the development of appropriate technology-enhanced OCLL environments which can satisfy learners' basic needs, especially the need for competence and autonomy, so that it can increase their intention to continue learning independently.

\subsection{Limitations and further research}

Despite the useful implications of this study, it also has some limitations. First, though the number of the participants and the variables fit the rule of thumb for performing a structural equation model (Hair et al., 2010), a larger sample size may result in more generalizable outcomes. Second, the data of this study was collected from Japanese undergraduate students, and since cultural and educational beliefs can affect the learner's motivation (Gardner, 2010), the same model can be further tested in other countries with different cultural and educational backgrounds. Third, application of the web-based e-portfolio system in this study limits the applicability of the findings to other settings, thus further research can address this issue by implementation of other technological devices.

Acknowledgements: We would like to sincerely acknowledge the Department of Applied Linguistics, Graduate School of International Cultural Studies (GSICS) of Tohoku University for their support during this study.

\section{References}

Baard, P. P., Deci, E. L., \& Ryan, R. M. (2004). Intrinsic need satisfaction: A motivational basis of performance and well-being in two work settings. Journal of Applied Social Psychology, 34(10), 2045-2068. http://dx.doi.org/10.1111/j.1559-1816.2004.tb02690.x

Bagozzi, R.P., \& Yi, Y. (1988). On the evaluation of structural equation models. Journal of the Academy of 
Fathali, S., \& Okada, T.

Marketing Science, 16(1), 74-94. http://dx.doi.org/10.1007/BF02723327

Barrett, H. C. (2006). Using electronic portfolios for classroom assessment. Connected Newsletter, 13(2), 4-6.

Barrett, H. C. (2007). Researching electronic portfolios and learner engagement: The reflect initiative. Journal of Adolescent \& Adult Literacy, 50(6), 436-449. http://dx.doi.org/10.1598/JAAL.50.6.2

Benson, P. (2001). Teaching and researching autonomy in language learning. Harlow, England: Longman. http://dx.doi.org/10.1057/9780230306790

Benson, P. (2011). Language learning and teaching beyond the classroom: An introduction to the field. In P. Benson \& H. Reinders (Eds.), Beyond the language classroom (pp. 7-16). New York: Palgrave Macmillan.

Chang, M. (2007). Enhancing web-based language learning through self-monitoring. Journal of Computer Assisted Language Learning, 23(3), 187-196. http://dx.doi.org/10.1111/j.1365-2729.2006.00203.x

Chen, K. C., \& Jang, S. J. (2010). Motivation in online learning: Testing a model of self-determination theory. Computers in Human Behavior, 26(4), 741-752. http://dx.doi.org/10.1016/j.chb.2010.01.011

Council of Europe. (2001). Common European framework of reference for languages: learning, teaching, assessment. Cambridge: Cambridge University Press. Retrieved from http://www.coe.int/en/web/portfolio/principles-and-guidelines-and-cefr

Deci, E. L. (1975). Intrinsic Motivation. New York: Plenum Press. http://dx.doi.org/10.1007/978-1-4613-4446-9

Deci, E. L., \& Ryan, R. M. (1985). Intrinsic motivation and self-determination in human behavior. New York: Plenum Press. http://dx.doi.org/10.1007/978-1-4899-2271-7

Deci, E. L., \& Ryan, R. M. (2010). Self-determination. In I. B. Weiner \& W. E. Craighead (Eds.), The Corsini encyclopedia of psychology (Vol. 4, pp. 1530 -1531). Hoboken, NJ: Wiley. http://dx.doi.org/10.1002/9780470479216.corpsy0834

Deci, E. L., Ryan, R. M., Gagne', M., Leone, D., Usunov, J., \& Kornazheva, B. P. (2001). Need satisfaction motivation and well-being in the work organizations of a former eastern bloc country. Personality and Social Psychology Bulletin, 27(8), 930-942. http://dx.doi.org/10.1177/0146167201278002

Ellis, R. (1994). The study of second language acquisition. Oxford, UK: Oxford University Press.

Fathali, S., \& Okada, T. (2016). On the importance of out-of-class language learning environments: A case of a web-based e-portfolio system enhancing reading proficiency. International Journal on Studies in English Language and Literature, 4(8), 77-85.

Fornell, C., \& Larcker, D. F. (1981). Evaluating structural equation models with unobservable variables and measurement error. Journal of Marketing Research, 18(1), 39-50. http://dx.doi.org/10.2307/3151312

Gardner, R. C. (2010). Motivation and second language acquisition: The socio-educational model. New York: Peter Lang.

Grolnick, W. S., Ryan, R. M., \& Deci, E. L. (1991). The inner resources for school performance: Motivational mediators of children's perceptions of their parents. Journal of Educational Psychology, 83(4), 508-517. http://dx.doi.org/10.1037/0022-0663.83.4.508

Hair, J., Black, W., Babin, B., \& Anderson, R. (2010). Multivariate data analysis. Upper Saddle River: Prentice Hall.

Hirata, Y. (2011). Evaluating web content for self-directed language learning. In G. Dettori \& D. Persico (Eds.), Fostering self-regulated learning through ICT (pp. 79-193). New York: Information Science Reference.

Hulland, J. (1999). Use of partial least squares (PLS) in strategic management research: A review of four recent studies. Strategic Management Journal, 20(2), 195-204. http://dx.doi.org/10.1002/(SICI)1097-0266(199902)20:2<195::AID-SMJ13>3.0.CO;2-7

Jeno, L. M., \& Diseth, A. (2014). A self-determination theory perspective on autonomy support, autonomous self-regulation, and perceived school performance. Reflecting Education, 9(1), 1-20.

Lai, C., \& Gu, M. (2011). Self-regulated out-of-class language learning with technology. Computer Assisted Language Learning, 24(4), 317-335. http://dx.doi.org/10.1080/09588221.2011.568417

Lai, C., Wang, Q., \& Lei, J. (2012). What factors predict undergraduate students' use of technology for learning? A case from Hong Kong. Computers \& Education, 59(2), 569-579.

http://dx.doi.org/10.1016/j.compedu.2012.03.006 
A self-determination theory approach to technology-enhanced out-of-class language learning intention

Lee, Y., Lee, J., \& Hwang, Y. (2015). Relating motivation to information and communication technology acceptance: Self-determination theory perspective. Computers in Human Behavior, 51, 418-428. http://dx.doi.org/10.1016/j.chb.2015.05.021

Lorenzo, G., \& Ittelson, J. (2005). An overview of e-portfolios. EDUCAUSE Learning Initiative, 1, 1-27.

McAuley, E., Duncan, T., \& Tammen, V. V. (1989). Psychometric properties of the intrinsic motivation inventory in a competitive sport setting: A confirmatory factor analysis. Research Quarterly for Exercise and Sport, 60(1), 48-58. http://dx.doi.org/10.1080/02701367.1989.10607413

Mobarhan, R., Majidi, M., \& Abdul Rahman, A. (2014). Motivation in electronic portfolio usage for higher education institutions. In H. Rahman \& R. D. Sousa (Eds.), Information systems and technology for organizational agility, intelligence, and resilience (pp. 224-243). Hershey: IGI Global. http://dx.doi.org/10.4018/978-1-4666-5970-4.ch011

Murphy, P., \& Alexander, P. (2000). A motivated exploration of motivation terminology. Contemporary Educational Psychology, 25, 3-53. http://dx.doi.org/10.1006/ceps.1999.1019

Neumeier, P. (2005). A closer look at blended learning parameters for designing a blended learning environment for language teaching and learning. ReCALL, 17(2), 163-178. http://dx.doi.org/10.1017/S0958344005000224

Okada, T., \& Sakamoto, Y. (2015). Dynamic lesson planning in EFL reading classes through a new e-learning system. In F. Helm, L. Bradley, M. Guarda, \& S. Thouësny (Eds.), Critical CALL-Proceedings of the 2015 EUROCALL Conference (pp. 444-449). Padova, Italy. http://dx.doi.org/10.14705/rpnet.2015.000373

Pintrich, P., \& Schunk, D. (2002). Motivation in education: Theory, research, and application. Upper Saddle River, NJ: Prentice-Hall.

Reinders, H. (2014). Personal learning environments for supporting out-of-class language learning. English Teaching Forum, 4, 14-19.

Richards, J. C. (2015). The changing face of language learning: Learning beyond the classroom. RELC Journal, 46(1), 5-22. http://dx.doi.org/10.1177/0033688214561621

Rivas, R. M. M. (1999). Reading in recent ELT course books. ELT Journal, 53(1), 12-21. http://dx.doi.org/10.1093/elt/53.1.12

Roca, J. C., \& Gagné, M. (2008). Understanding e-learning continuance intention in the workplace: A self-determination theory perspective. Computers in Human Behavior, 24(4), 1585-1604. http://dx.doi.org/10.1016/j.chb.2007.06.001

Schunk. D., \& Zimmerman, B. (2006). Competence and control beliefs: Distinguishing the means and the ends. In P. Alexander \& P. Winne (Eds.), Handbook of educational psychology (pp. 349-367). Mahwah, NJ: L. Erlbaum.

South, S. E. (2006). Contributing factors to engagement in online learning environments: The relationship between sense of community and participation. Unpublished doctoral dissertation, University of Arizona, Tucson, Arizona, United States.

Standage, M., Duda, J. L., \& Ntoumanis, N. (2005). A test of self-determination theory in school physical education. British Journal of Educational Psychology, 75(3), 411-433. http://dx.doi.org/10.1348/000709904X22359

Urdan, T., \& Turner, J. C. (2005). Competence motivation in the classroom. In A. J. Elliot \& C. S. Dweck (Eds.), Handbook of competence and motivation (pp. 297-317). New York: Guilford.

Vallerand, R. J. (1997). Toward a hierarchical model of intrinsic and extrinsic motivation. Advances in Experimental Social Psychology, 29, 271-360. http://dx.doi.org/10.1016/S0065-2601(08)60019-2

Vallerand, R. J., \& Bissonnette, R. (1992). Intrinsic, extrinsic, and amotivational styles as predictors of behavior: A prospective study. Journal of Personality, 60(3), 599-620. http://dx.doi.org/10.1111/j.1467-6494.1992.tb00922.x

Venkatesh, V., Morris, M., Davis, G., \& Davis, F. (2003). User acceptance of information technology: Toward a unified view. MIS Quarterly, 27(3), 425-478.

Yoon, C., \& Rolland, E. (2012). Knowledge-sharing in virtual communities: Familiarity, anonymity and 
Fathali, S., \& Okada, T.

self-determination theory. Behavior \& Information Technology, 31(11), 1133-1143.

http://dx.doi.org/10.1080/0144929X.2012.702355

Yoon, T. (2012). Are you digitized? Ways to provide motivation for ELLs using digital storytelling. International Journal of Research Studies in Educational Technology, 2(1), 25-34.

Zhou, M. (2016). Chinese university students' acceptance of MOOCs: A self-determination perspective.

Computers \& Education, 92, 194-203. http://dx.doi.org/10.1016/j.compedu.2015.10.012 